\title{
РЕФОРМЫ В СИСТЕМЕ ПУБЛИЧНОГО УПРАВЛЕНИЯ В РОССИИ: ЦЕЛИ, НАПРАВЛЕНИЯ, РЕЗУЛЬТАТЫ
}

\begin{abstract}
АНнотАция. В ХХ в. имело место усложнение функций современного административно-государственного управления. Наряду с традиционными задачами обслуживания, регулирования и лицензирования, т. е. осуществления регулирующих функций, появились принципиально новые задачи, связанные с принятием решений в разных сферах жизни общества. Государственное управление на основе беспристрастной законодательно выверенной системы и современных технологий является для России желаемой целью. Для достижения этой цели необходимо развитие теории государственного управления, способной обосновать методологию построения этого вида социальной деятельности и определить ориентиры системной реформы государственного аппарата и обеспечивающих его институтов и механизмов. Однако, несмотря на целесообразность экономии бюджетных расходов, необходимо понимать, что эффективная государственная служба со своими специфическими стандартами и критериями эффективности необходима даже максимально децентрализованной общественной системе.

КЛЮчЕВЫЕ СЛОВА. Публичное управление; публичная служба; административная реформа; публичный сектор; государственное управление; муниципальное управление. ИНФОРМАЦИЯ О СТАТЬЕ. Дата поступления 6 апреля 2016 г.; дата принятия к печати 20 апреля 2016 г.; дата онлайн-размещения 31 мая 2016 г.
\end{abstract}

Ye. R. Meteleva Baikal State University, Irkutsk, Russian Federation

\section{REFORMS IN RUSSIAN PUBLIC ADMINISTRATION SYSTEM: OBJECTIVES, DIRECTIONS, RESULTS}

\begin{abstract}
The XX-th century saw complicacy of functions of contemporary public administrative and governmental management. Along with traditional tasks of service, regulation and licensing, that is, implementation of regulating functions, there arise principally new tasks connected with decision-making in various spheres of public life. Public administration on the basis of impartial legally adjusted system and modern technologies is a desirable objective for Russia. To achieve this objective, it is necessary to develop the public administration theory able to substantiate the methodology of building this type of social activity and determine the milestones of the system reform for the government machinery and the institutions and mechanisms that provide it. However, in spite of the practicability of budget expenditure saving, it is necessary to realize that the effective and efficient public service with its specific standards and criteria of efficiency is vital even for the most decentralized public system.

KEYWORDS. Public administration; public service; reform of administration; public sector; state administration; municipal administration.

ARTICLE INFO. Received April 6, 2016; accepted April 20, 2016; available online May 31, 2016.
\end{abstract}

Публичное (государственное и муниципальное) управление - это деятельность аппарата публичной власти по решению общих для общества данной страны задач. Это деятельность по выполнению регулирующих функций, среди которых основными являются национальная оборона, поддержание порядка, разрешение конфлик-

(C) Е.Р. Метелева, 2016

\section{Baikal Research Journal}


тов, защита прав и свобод граждан, строительство и содержание транспортной инфраструктуры, установление «правил игры» в экономической сфере. Эти функции традиционно выполнялись на протяжении всего периода существования государства как сложившейся «машины», механизма, аппарата.

В XX в. по определенным причинам государство активно начало расширять свое присутствие в экономике. $К$ традиционным функциям добавились новые виды деятельности. Государство широко присутствует теперь в социальной сфере (здравоохранение, образование, социальная защита, культура) и отвечает не только за состояние дорожно-транспортной инфраструктуры, но и за энергосети, водоснабжение, телекоммуникации.

В 70-х гг. в западных странах начались процессы реформирования публичной службы (аппарата публичной власти). Созданный несколько тысячелетий назад для осуществления регулирующих функций этот аппарат в начале XX в. был переформатирован согласно принципам, сформулированным М. Вебером. В соответствии с его концепцией «идеальной бюрократии», аппарат публичной власти, или как его называют западные исследователи, «администрация», организован с помощью законов и прочих нормативных актов, осуществляется на принципах законности, профессионализма, беспристрастности, формальной обезличенности. Обезличенный характер правил и процедур обеспечивает подробное понимание и исполнение функций, предписывает необходимый вид поведения публичных служащих.

Однако, по мнению западных исследователей, в работе администрации проявляются несколько важных дисфункций. Первая дисфункция заключается в том, что власть принятия решений при бюрократической организации имеет тенденцию концентрироваться на том уровне («в тех руках»), где предпочтения отдаются стабильности. Бюрократический тип организации не подлежит изменению, нововведениям, так как лица, принимающие решения, стремятся к сохранению статус-кво, избегают перемен.

Вторая дисфункция, по мнению экспертов, состоит в том, что централизация процесса принятия решений усиливает иерархический тип организации. Никто ни с кем не коммуницирует, в системе преобладают вертикальные связи (руководства-подчинения), практически отсутствуют горизонтальные коммуникации между функциональными подсистемами.

Следующая дисфункция, свойственная бюрократической организации, - это развитие параллельной власти. Возникают привилегированные группы внутри любой бюрократической организации. Например, во Франции всемирно известная и очень престижная Национальная школа администрирования (École Nationale d'Administration - ÉNA) формирует параллельную структуру власти, состоящую из ее выпускников («энархов») [1].

Администрация, будучи всего лишь инструментом, не может функционировать безотносительно к чьим-либо ценностям, не работая на чьи-либо интересы. Вся административная работа движется по приказу руководителя (министра, начальника службы, департамента и т. д.). Получается, что административная система служит тем, кто знает, как ее использовать. Это значит, что большинство граждан исключаются из системы и не получают всей возможной помощи, так как не знают, как она работает.

Другой факт, на который призывают обратить внимание эксперты - юридический. Администрация в основном акцентируется на форме, а не на содержании. Функционирование администрации основано на правилах, управляется правилами. Однако большинство граждан часто не обладают достаточным временем и уровнем образования, чтобы знать многочисленные требования и правила, что также ограничивает их возможности использования административного аппарата в своих

\section{Baikal Research Journal}


интересах [1]. Начатые в 1970-х гг. в западных странах реформы, по утверждениям их организаторов, способствовали нейтрализации названных дисфункций.

Нам представляется целесообразным особо акцентировать некоторые важные аспекты реформ в системе публичного управления. Система публичного управления как система деятельности включает в себя две деятельностные подсистемы:

- во-первых, это система деятельности органов государственной власти и местного самоуправления, которые осуществляют регулирующие функции;

- во-вторых, это система деятельности государственных и муниципальных организаций (предприятий, учреждений), которые оказывают публичные услуги.

Трудно сказать, с чем в большей степени связано непонимание и игнорирование этого факта - то ли с трудностями перевода, то ли с недостаточно внимательным знакомством с зарубежным опытом, - но российские реформаторы весьма своеобразно заимствовали этот опыт. Они «увидели» только одну часть проводимых западными странами реформ и механически спроецировали эту часть на совершенно другой объект реформирования.

Для иллюстрации данного тезиса обратимся к фундаментальному изданию «Эффективность государственного управления» [2]. Данный труд - результат коллективного труда американских ученых и практиков, посвященный вопросам повышения эффективности деятельности публичных организаций, переведенный с английского языка и изданный в России в 1998 г. В этой монографии объемом более 800 с. теоретические подходы и практические решения проблем оценки эффективности публичного управления рассмотрены очень подробно и всесторонне, но во всем этом объемном труде практически не встречаются примеры оценки «эффективности и результативности" деятельности органов государственной власти или местного самоуправления. Хочется привести цитату Дж. Буркса: «Основное предназначение органа местного самоуправления состоит не в том, чтобы... пересматривать форму и порядок получения государственных бумаг или увольнять начальников муниципальных служб, а в том, чтобы обеспечивать высокий уровень здравоохранения, образования, безопасность, удобство и благополучие местного населения... Поэтому нормы эффективности должны рассматриваться через призму работы местных служб жизнеобеспечения, а не избирательных законов или законной силы выданных документов» [3]. В то же время российская «административная реформа» практически полностью нацелена на повышение «эффективности и результативности" деятельности именно публичных органов.

Далее следует отметить еще один спорный момент российских реформ. В российской теории государственного управления практически не используется термин «публичный сектор». В данный сектор входят все сферы деятельности и отношения собственности, которые не относятся к частному и общественному (некоммерческому, третьему) секторам. По данным американской статистики, около 40 \% занятых в США - работающие в публичном секторе [2]. Это не только сотрудники органов публичного управления (от федерального до местного уровня), но и работники, обслуживающие объекты инфраструктуры, находящейся в госсобственности, занятые в сфере социального обслуживания, организациях жилищно-коммунального хозяйства, сфере образования, здравоохранения, армии, полиции, пенитенциарной системы, пожарной охране и т. д.

Деятельность этих структур финансируется из бюджетов различных уровней, и это является основным критерием отнесения их к публичному сектору. Все они находятся в непосредственном административном подчинении органов публичного управления, поэтому в английском и в основных европейских языках используется термин «публичное администрирование», очень вольно переведенный на русский язык как «государственное и муниципальное управление» .

\section{Baikal Research Journal}

электронный научный журнал Байкальского государственного университета 
Так вот, реформирование, проводимое в западных странах, направлено на весь этот публичный сектор, даже точнее, на изменение деятельности (повышение производительности) государственных и муниципальных организаций (предприятий, учреждений), а не на перестройку деятельности органов государственного и муниципального управления, чему собственно и посвящена российская «административная реформа» .

Еще одна понятийная путаница возникла в связи с тем, что в западной теории и практике есть понятие «публичная служба» («государственная служба» + «муниципальная служба») и понятие «публичные службы» («государственные службы» + «муниципальные службы»). Под первой понимается деятельность, осуществляемая всеми публичными служащими (в число которых входят как работники органов публичной власти, так и работники государственных и муниципальных предприятий, военные, полицейские, учителя, врачи, пожарные, библиотекари и т. д.). Под вторыми понимаются сами государственные и муниципальные организации (предприятия, учреждения). И нужно констатировать, что в рамках концепции «нового публичного менеджмента» (англо-саксонский вариант) или «новой административной политики» (европейский вариант) идет процесс реформирования, прежде всего, деятельности публичных служб и в гораздо меньшей степени - органов государственной власти и местного самоуправления. Так, в указанном фундаментальном труде, посвященном вопросам эффективности, например, сказано, что «были предложены нормативы для измерения результатов работы учреждений пожарной охраны, здравоохранения, полиции и общественных работ. Цель преследовалась одна - помочь органам власти в оценивании работы этих подразделений... и, в соответствии с ролью граждан в повышении эффективности управления, помочь им оценивать органы управления на выборах» [2].

Деятельность самих органов публичной власти затрагивается реформами в наименьшей степени. В той же монографии также отмечается, что «нормативы и стандарты применимы лишь к немногим видам работ, выполняемых органами государственного управления, прежде всего, например, к рутинным операциям... В отношении работ, в которых нет или почти нет рутины, возникает проблема оценки реальной эффективности, а тем самым создается “оценочный тупик” " [2].

Однако если мы обратимся к направлениям «административной реформы» в Российской Федерации, то увидим следующее:

- снижение избыточного государственного регулирования;

- рост качества государственных услуг (под которыми понимается именно деятельность органов власти);

- повышение эффективности органов власти (все-таки органов власти, а не публичных предприятий и учреждений);

- увеличение информационной открытости ${ }^{1}$.

Нам представляется более обоснованным говорить о широкой реформе публичного сектора, осуществляемой в России на протяжении последних 20-25 лет, которая включает в себя следующие составляющие:

- реформу государственной службы;

- административную реформу;

- реформу здравоохранения;

- реформу образования;

- пенсионную реформу;

- реформу системы социального обеспечения;

- реформу жилищно-коммунального хозяйства;

- реформу армии;

${ }^{1}$ Министерство экономического развития Российской Федерации [Электронный ресурс] : офиц. сайт. URL : http://economy.gov.ru/minec/activity/sections/.

\section{Baikal Research Journal}


- реформу полиции;

- ряд других, более частных реформ.

Основным федеральным органом исполнительной власти, отвечающим за проведение части этих реформ, выступает Министерство экономического развития. Так, из 44 направлений его деятельности, обозначенных на официальном сайте, 16 можно охарактеризовать как имеющие отношение к общей реформе публичного сектоpa, в том числе касающиеся стратегического и пространственного планирования, контрактной системы, программно-целевого планирования, государственно-частного партнерства, электронного правительства, оценки эффективности реализации программ и регулирующего воздействия, противодействия коррупции ${ }^{2}$.

Общими декларируемыми целями всей этой совокупности реформ (или одной большой реформы) публичного сектора являются ограничение «чрезмерного» вмешательства государства в экономику (так называемое снижение избыточного государственного регулирования), сокращение (так называемая «оптимизация») расходов публичных бюджетов всех уровней, повышение «эффективности и результативности» деятельности органов и организаций публичного сектора.

Надо признать, что эти цели, по сути, являются продолжением тотального разгосударствления, перехода от административно-командной к рыночной системе хозяйствования. За последние 25 лет в России имела место радикальная смена модели государственной политики, экономической и социальной. Кстати говоря, подобная тенденция также наблюдается в западных странах, традиционно отличающихся высоким уровнем экономического развития и социального обеспечения. Так, король Нидерландов в конце 2013 г. объявил о конце государства всеобщего благоденствия. Монарх предложил вместо него построить «общество активного участия» (participation society), предполагающее, главным образом, сокращение социальных расходов государства и повышение ответственности за собственное благосостояние самих голландцев [4].

Финляндия отказывается от якобы «громоздкой и дорогостоящей» системы социального обеспечения и вводит систему единого безусловного дохода всем гражданам страны. То же самое внедряет у себя и Швейцария. Даже на первый, достаточно поверхностный, взгляд, эта система означает отказ от дифференцированного подхода к особым категориям граждан (социально незащищенным) и приведет к ухудшению их социального положения.

Если вникнуть в суть происходящих реформ, то выясняется, что государство отказывается от выполнения уже не только публичных услуг, которые все чаще передаются от публичных (государственных и муниципальных) частным организациям, но и от выполнения регулирующих функций. Ведь совершенно не напрасно, не случайно и не бездумно в России в Федеральном законе «Об организации предоставления государственных и муниципальных услуг» от 27 июля 2010 г. № 210-ФЗ ${ }^{3}$ определено, что это не публичные организации (предприятия, учреждения), а именно органы публичной власти «предоставляют услуги», т. е. произведена сознательная подмена понятий: вместо «регулирующих функций» - «публичные услуги» .

Под это действие - подмену понятий - в западных исследованиях подводится «теоретическое обоснование». Публичная служба создается и существует, поскольку она необходима, даже когда данной деятельностью может заниматься частный сектор. Деятельность частного сектора регулируется прибылью и направлена на удовлетворение потребностей, запросов каждого клиента. Публичная служба служит другим целям и характеризуется другими средствами; она является набором

${ }^{2}$ URL : http://economy.gov.ru/minec/activity/sections/.

${ }^{3}$ Об организации предоставления государственных и муниципальных услуг : федер. закон РФ от 27 июля 2010 г. № 210-Ф3 // Российская газета. 2010. 30 июля.

\section{Baikal Research Journal}


служб, которые удовлетворяют общие требования населения, но не индивидуальные запросы (потребности) [5].

Публичная служба в некоторых случаях учитывает также и индивидуальные потребности населения, но в основном направлена на удовлетворение неких общих требований. Гражданин имеет установленные законодательством права и предъявляет их в качестве требований: поезда должны ходить по расписанию, почта должна доставляться вовремя, дети должны получать школьное образование.

Для выполнения требований публичная служба должна иметь определенные прерогативы. Публичная служба берет на себя прерогативы публичной власти. Разновидностью этой власти является полиция, использование общественных площадей, возможность что-либо экспроприировать в целях реализации «общего интереса» (еще один концепт западной теоретической мысли, который совершенно не известен в России).

Разумеется, всегда имеется неравенство публичной службы по сравнению с частным сектором, оказывающим те же услуги. Частный сектор не имеет права экспроприировать, не может вводить специальные налоги или взимать сборы. Это неравенство объясняется важностью «общего интереса». Традиционно «общий интерес» концентрируется вокруг понятия публичной службы. Услуги, которые обеспечиваются публичным сектором, в принципе могут оказываться и частным сектором (услуги по удовлетворению потребностей). Не исключено, что частный сектор также иногда обеспечивает реализацию и некоторых общих требований, однако в основном он удовлетворяет индивидуальные потребности. По этой причине именно публичный сектор получает определенные преимущества.

Во все времена администрация представляла собой структуру, в которой преобладала функция контроля. Раньше администрация была жестко ограничена правилами, а в рамках реформы в западных странах попытались дать административному аппарату больше свободы, возможность отойти от правил и действовать более самостоятельно и гибко. Это назвали революцией публичной службы.

В конце XX - начале XXI в. наступил период, когда от государства ожидается то, что от него не требовалось никогда. Экспертами это расценивается как кризис, так как государство не может выполнять все свои прежние функции. Эта неспособность государства часто объясняется отсутствием финансов из-за внутренних и внешних долгов [5].

В ответ на данный кризис на Западе появилась тенденция дерегуляции. Дерегуляция - это масштабная и долгосрочная программа. Принцип ее таков: когда возникают проблемы, публичные вопросы, которые государство не в состоянии решить, тогда и применяется дерегуляция [1].

Административное регулирование, которое относится к некоторым сферам публичной службы (социальная защита, условия труда, защита покупателей, охрана окружающей среды, торговля), становится объектом дерегуляции. В условиях глобализации, видя дерегуляцию в других странах, предприниматели в данной стране начинают обсуждать, не слишком ли широко их национальное государство вмешивается в экономическую жизнь. Отсутствие тенденций дерегуляции в итоге приводит к оттоку инвестиций в другие страны, где бизнесу предоставлено больше свобод. Таким образом, дерегуляция стала, в определенном смысле, инструментом конкурентной борьбы между странами.

Оппоненты в самих западных странах возражают, что нельзя рынок предоставлять самому себе. В рынке тоже есть определенные дисфункции, которые ярко выявил мировой кризис конца $2000-$ х гг. Тем не менее, большинство экспертов настаивают на том, что если государство желает выступать стабилизатором экономики, то надо больше думать о дерегуляции и не очень надеяться на публичное регулирова-

\section{Baikal Research Journal}


ние. Например, почта в Бельгии была государственной, а стала негосударственной. Бывшая публичная почта должна теперь выдерживать конкуренцию. В результате доставка корреспонденции стала производиться быстрее, что повысило удовлетворенность граждан [1].

В европейской публичной службе в 1990-х гг. стал вводиться контрактный менеджмент. Это означало отход от старых традиций, которые раньше квалифицировали все функции как публичные. По контракту бывшие публичные функции активно передаются за пределы публичных структур. Это особенно заметно в секторе соцзащиты.

Государство стало «ограничивать себя» и многое отдавать на откуп рынку (так называемый Римский договор). В оборот вошло новое понятие «общая / универсальная служба» (Universal service) - более узкое понятие, чем публичная служба [1].

Общие/ универсальные службы оказывают услуги, например, связи, электричества, водоснабжения, при этом граждане платят им меньше, чем платили бы коммерческим организациям. Действует принцип солидарности - все платят фиксированную сумму денег, независимо от потребителя (сумма платежа рассчитывается как фиксированный тариф, умноженный на потребляемое количество). Универсальность понимается как средство дать всем людям возможность получить определенный объем услуг.

Сейчас публичная служба приблизилась по правилам деятельности к частному сектору. Публичная администрация сталкивается со схожими трудностями, например, международным разделением труда, ростом дефицита бюджета, изменением системы ценностей граждан. Вот такие теоретическая база и наработанная практика имелись в распоряжении организаторов российских реформ и были ими применены в процессе реформы отечественного публичного управления.

Однако рациональные, на первый взгляд, идеи в конечном итоге завершаются в России весьма неудовлетворительными результатами. Так, согласно отчету счетной палаты за 2015 г., оптимизация медицинских учреждений в России привела к росту смертности пациентов на $2,6 \%$ в среднем по стране. Ожидаемого роста эффективности и доступности медпомощи также не произошло. В рамках так называемой «оптимизации» было сокращено значительное количество медработников, что привело к дефициту квалифицированной медицинской помощи, а в отдаленных и труднодоступных местностях - к ее полному отсутствию ${ }^{4}$.

Кстати говоря, вызвавшая так много споров реформа здравоохранения, предложенная президентом США Б. Обамой, в качестве основной меры предполагает обязательное приобретение медицинской страховки всеми гражданами без исключения (с частичным государственным участием для малоимущих), т. е. то же самое перекладывание ответственности за финансирование и организацию публичных услуг на плечи самих граждан.

По свидетельству председателя профсоюза медработников «Действие» Е. Чацкой, в больницах по всей стране не хватает врачей, особенно терапевтов. «Оптимизация» привела к сокращению ставок и росту нагрузки на одного врача. Нехватка медицинских кадров в отдельных регионах страны достигает 50 \% [6].

Реформирование в сфере образования привело к не менее серьезным негативным последствиям. В системе общего образования вводится принцип вариативности, ориентирующий на максимальную индивидуализацию образования [7]. Идея состоит в том, что каждый человек (ученик) может получить то образование, которое он «хочет» и к которому имеет «склонности», чтобы затем трудиться именно в конкретной, заранее выбранной сфере профессиональной деятельности. Этот принцип противопоставлен советскому принципу универсального образования, когда

${ }^{4} \mathrm{CП}$ : оптимизация в здравоохранении привела к ухудшению качества услуг [Электронный ресурс] // МИА «Россия сегодня». URL : http://ria.ru/society/20150413/1058320929.html.

\section{Baikal Research Journal}

электронный научный журнал Байкальского государственного университета 
все получали именно «общее образование». Очередная подмена понятий - вместо «знаний» выпускники школ и вузов приобретают «компетенции» - нацелена на подготовку узкоспециализированных работников, которые должны встраиваться в сферы производства и потребления товаров и услуг. Как кратко и емко разъяснил начавший реформу министр образования А. Фурсенко, «недостатком советской системы образования была попытка формирования человека-творца, а сейчас наша задача заключается в том, чтобы вырастить квалифицированного потребителя» ${ }^{5}$.

Соответственно, цели формирования зрелой, общественно-полезной личности, ответственного гражданина, готового к созидательному труду, современное российское государство больше не ставит. В итоге российские школьники стали проигрывать на международных олимпиадах, что говорит об успешном достижении правительством своих целей. На Международной математической олимпиаде, начиная с 2011 г., россияне ни разу не поднялись выше 4-го места, а в 2015 г. заняли 8-е место. Если раньше в ходе сдачи единого государственного экзамена задачи чуть меньшей сложности решали 50 \% учеников школ страны, то сейчас - только $10 \%$, остальные оказываются не в состоянии это сделать [8].

В ближайшее время в образовании и медицине будет внедрена система «эффективных контрактов», которая, по мнению экспертного сообщества, поможет окончательно разрушить эти две базовых инфраструктуры любого общества. «Эффективный контракт» основан на оценке «эффективности», но в сфере услуг, тем более в отношении образовательных и медицинских услуг, измерение эффективности представляет собой сложнейшую задачу, которая до сих пор не имеет полноценного и убедительного решения [9].

В то же время ставшие доступными в последнее время аналитические материалы американского Комитета по вопросам науки, посвященные изучению научно-технического обучения и кадровых резервов в СССР, ясно показывают, насколько высоко наши идеологические противники оценивали советскую систему образования [10]. При этом так рекламируемый сейчас опыт финской системы образования, занимающей высокие позиции в рейтинге некой Programme for International Student Assessment (Международная программа по оценке образовательных достижений учащихся), не приносит данной стране призовых мест на международных олимпиадах школьников, а также достижений в разных сферах народного хозяйства, хотя бы близко сопоставимых с результатами СССР ${ }^{6}$.

Возможные перспективы российской системы высшего образования можно увидеть, обратившись к практике соседней страны - Казахстана. С 2017 г. государственная аттестация вузов в этой стране будет прекращена, и каждый частный вуз будет выдавать дипломы собственного образца. Заявленная цель такой «реформы» - повышение конкурентоспособности казахских вузов в мировом образовательном пространстве [11].

Ведущаяся примерно в том же направлении реформа российской высшей школы пока не приносит ожидаемых результатов, и можно уверенно прогнозировать, что и не принесет. Пока результаты таковы: по оценке Счетной палаты, выделенные бюджетные средства потрачены неэффективно. Ни одно образовательное учреждение, получившее государственные субсидии, общий объем которых составил 29 млрд р., не вошло в сотню лучших вузов мира ${ }^{7}$.

${ }^{5}$ Фурсенко честно рассказал о целях реформы образования [Электронный pecypc] // Pravda-TV. URL : http://www.pravda-tv.ru/2012/04/19/14237/14237.

${ }^{6}$ Реформу среднего образования в Финляндии уже назвали «революционной» [Электронный ресурс] // ИА REGNUМ. URL : http://regnum.ru/news/society/1908855.html.

${ }^{7}$ Аудиторы признали провал российских вузов, которым дали 29 млрд рублей [Электронный ресурс] // Известия. 2016. 13 янв. URL : http://izvestia.ru/news/601549.

\section{Baikal Research Journal}

электронный научный журнал Байкальского государственного университета 
Очевидным по результатам анализа всех этих реформ публичного сектора в России является только один факт: происходит целенаправленный отказ от осуществления регулирующих функций и передача все больших зон ответственности в руки частного сектора. В связи с этим можно указать на одно из известных, наиболее всеобъемлющих сравнительных исследований экономической эффективности публичного и частного производства товаров / предоставления услуг. В соответствии с его выводами, предоставление услуг публичным сектором не уступает деятельности частного сектора, если не превосходит ее, особенно если учитывать трансакционные издержки, возникающие при предоставлении услуг внешним исполнителям в форме аутсорсинга в связи с проведением конкурса, переговорами и отбором производителей, а также контролем процесса предоставления услуг (мониторингом) и оценкой со стороны публичного заказчика [12].

Объективный анализ свидетельствует о том, что положительного эффекта от сжатия публичного сектора для общества, для граждан не наблюдается. Возникает вопрос, кому же выгодно подобное «реформирование», в чьих интересах оно осуществляется. Ответ может быть однозначным - только в интересах частного сектора, крупного бизнеса, который один только и остается в выигрыше от снижения объемов государственного вмешательства в экономику.

\section{Список использованной литературы}

1. Грар А. Административные реформы в Бельгии и Франции : лекция в рамках проекта TACIS EDRUS-9517 / A. Грар. - Париж, 1997. - (Док. опубл. не был).

2. Эффективность государственного управления : пер. с англ. / под общ. ред. С. А. Батчикова, С. Ю. Глазьева. - М. : Фонд «За экономическую грамотность» : Российский экономический журнал : Консалтбанкир, 1998. - 848 с.

3. Burks J. Efficiensy standards in municipal management / J. Burks // National Municipal Review. - 1912. - Vol. 1, № 3. - P. 364-371.

4. Ратников А. Тюльпан завял: король Нидерландов объявил о завершении эпохи «всеобщего благосостояния» [Электронный ресурс] / А. Ратников. - Режим доступа : https://lenta. $\mathrm{ru} /$ articles $/ 2013 / 09 / 19 /$ netherlands/.

5. Скарамуццо Н. Административная политика : лекция в рамках проекта TACIS EDRUS-9517 / Н. Скарамуццо. - Иркутск, 1998. - (Док. опубл. не был).

6. Чацкая Е. Врачи уходят из больниц. Условия работы стали невыносимыми [Электронный ресурс] / Е. Чацкая. - Режим доступа : http://rus2web.ru/mneniya/vrachi-uxodyat-izbolnicz.-usloviya-rabotyi-stali-nevyinosimyimi.html.

7. Расинский П. Пиррова победа вариативности [Электронный ресурс] / П. Расинский. URL : https://gazeta.eot.su/article/пиррова-победа-вариативности.

8. Добрынин С. Нетающий айсберг: о чем говорит неудачное выступление сборной России на Международной математической олимпиаде? [Электронный ресурс] / С. Добрынин. - Режим доступа : http://www.svoboda.org/content/article/27171978.html.

9. Черняховский С. Система «эффективных контрактов» добьет отечественное образование и медицину [Электронный ресурс] / С. Черняховский. - Режим доступа : http:// www.km.ru/v-rossii/2013/02/19/zdravookhranenie-i-meditsina-v-rossii/704316-sistemaeffektivnykh-kontraktov-dob.

10. Мэндэрс Ц. Р. С. Научно-техническое образование и кадровые резервы в СССР [Электронный ресурс] : аналит. записка НАТО 1959 г. / Ц. Р. С. Мэндэрс. - Режим доступа : http://statehistory.ru/4316/Analiticheskaya-zapiska-NATO-ob-obrazovanii-v-SSSR1959 -g-/.

11. Салимов Д. Учу, учу, кого и как хочу... [Электронный ресурс] / Д. Салимов. - Режим доступа : http://exclusive.kz/uchu-_uchu-_kogo_i_kak_hochu.html.

12. Bel German Does privatization of solid waste and water services reduce costs? A review of empirical studies / German Bel, M. Warner // Resources, Conservation and Recycling. 2008. - Vol. 52. - P. 1337-1348.

\section{Baikal Research Journal}




\section{References}

1. Grar A. Administrativnye reformy $v$ Bel'gii i Frantsii: lektsiya $v$ ramkakh proekta TACIS EDRUS-9517 [Administrative reforms in Belgium and France: a lecture in terms of the TACIS EDRUS-9517 project, Paris, 1997]. (The document was not published).

2. Batchikov S. A., Glazyev S. Yu. (eds). Effektivnost' gosudarstvennogo upravleniya [Efficiency of public administration]. Moscow, "For Economic Literacy" Fund Publ., Russian Economic Journal Publ., Konsaltbankir Publ., 1998. 848 p.

3. Burks J. Efficiensy standards in municipal management. National Municipal Review, 1912, vol. 1 , no. 3, pp. 364-371.

4. Ratnikov A. Tyul'pan zavyal: korol' Niderlandov ob"yavil o zavershenii epokhi «vseobshchego blagosostoyaniya» [The tulip has withered: the king of the Netherlands has declared about completion of the "commonwealth" epoch]Available at: https://lenta.ru/articles/2013/09/19/ netherlands/. (In Russian).

5. Skaramutstso N. Administrativnaya politika: lektsiya $v$ ramkakh proekta TACIS EDRUS-9517, Irkutsk, 1998 [Administrative policy: a lecture in terms of the TACIS EDRUS-9517 project, Irkutsk, 1998]. (The document was not published).

6. Chatskaya E. Vrachi ukhodyat iz bol'nits. Usloviya raboty stali nevynosimymi [Doctors are leaving hospitals. Conditions of work have become unbearable. ]. Available at: http://rus2web.ru/ mneniya/vrachi-uxodyat-iz-bolnicz.-usloviya-rabotyi-stali-nevyinosimyimi.html. (In Russian).

7. Rasinsky P. Pirrova pobeda variativnosti [Pyrrhic victory of variability]. Available at: https://gazeta.eot.su/article/пиррова-победа-вариативности. (In Russian).

8. Dobrynin S. Netayushchii aisberg: o chem govorit neudachnoe vystuplenie sbornoi Rossii na Mezhdunarodnoi matematicheskoi olimpiade? [A nonmelting iceberg: what does the unlucky demonstration of Russia's team in the International Mathematical Olympiad testify?]. Available at: http://www.svoboda.org/content/article/27171978.html. (In Russian).

9. Chernyakhovsky C. Sistema «effektivnykh kontraktov» dob'et otechestvennoe obrazovanie $i$ meditsinu [System of "effective contracts" will finish off national education and medicine]. Available at: http://www.km.ru/v-rossii/2013/02/19/zdravookhranenie-i-meditsina-v-rossii/704316-sistema-effektivnykh-kontraktov-dob. (In Russian).

10. Menders Ts. R. S. Nauchno-tekhnicheskoe obrazovanie i kadrovye rezervy $v$ SSSR: Analiticheskaya zapiska NATO ob obrazovanii $v$ SSSR [Scientific and technical education and personnel reserve in the USSR: A NATO analytical note of education in the USSR]. Available at: http://statehistory.ru/4316/Analiticheskaya-zapiska-NATO-ob-obrazovanii-v-SSSR-1959-g-/. (In Russian).

11. Salimov D. Uchu, uchu, kogo i kak khochu ... [Teaching, teaching, someone and somehow...] Available at: http://exclusive.kz/uchu-_uchu-_kogo_i_kak_hochu.html. (In Russian).

12. Bel German, Warner M. Does privatization of solid waste and water services reduce costs? A review of empirical studies. Resources, Conservation and Recycling, 2008, vol. 52, pp. 1337-1348.

\section{Информация об авторе}

Метелева Елена Растиславна - доктор экономических наук, профессор, кафедра экономики и государственного управления, Байкальский государственный университет, 664003, г. Иркутск, ул. Ленина, 11, e-mail: elenameteleva@ya.ru.

\section{Author}

Yelena R. Meteleva - Doctor habil. (Economics), Professor, Chair of Economics and Public Administration, Baikal State University, 11 Lenin St., 664003, Irkutsk, Russian Federation; e-mail: elenameteleva@ya.ru.

\section{Библиографическое описание статьи}

Метелева Е. Р. Реформы в системе публичного управления в России: цели, направления, результаты / Е. Р. Метелева // Baikal Research Journal. - 2016. — T. 7, № 3. - DOI : 10.17150/2411-6262.2016.7(3).19.

\section{Reference to article}

Meteleva Ye. R. Reforms in Russian public administration system: objectives, directions, results. Baikal Research Journal, 2016, vol. 7, no. 3. DOI : 10.17150/2411-6262.2016.7(3).19. (In Russian).

\section{Baikal Research Journal}

